\title{
Female genital mutilation: three questions for us to consider
}

\section{Susan Quilliam}

Freelance Writer, Broadcaster, Consultant and Trainer, Cambridge, UK

\section{Correspondence to} Ms Susan Quilliam; susan@susanquilliam.com; http://susanquilliam.com

Received 13 May 2015 Accepted 13 May 2015

\section{CrossMark}

To cite: Quilliam S. J Fam Plann Reprod Health Care 2015:41:235-237.

\section{BACKGROUND}

It was 1985 and I was running a workshop for health professionals on the frontline of delivering cervical smear tests. A woman rose to give an impassioned plea that genital examinations should "offer respect and compassion to cut women like myself". We listened attentively to her words, nodded courteously; the discussion then moved on.

Later, as participants were leaving, I overheard the comments: "What does she mean 'cut women'?", "Surely that's not a problem in Britain?" and "What should you do?" To my shame, I felt the same ignorant, confused and unsure of my ground. 'Female circumcision', as it was then called, was an alien idea. If we did grasp the concept it was taken to mean the equivalent of male circumcision - a process that while invasive, was likely to be acceptable in its cultural context and was in many ways none of our business.

Fast forward three decades and what is now known as female genital mutilation (FGM) - note the change in terminology - is a high-profile issue and illegal in the UK. Are we any clearer, more informed or more resourced? I asked ten UK-based health professionals, from varying sexual health fields and cultural backgrounds, to offer opinions - often based on their knowledge of colleagues' attitudes as well as their own. The results make for interesting reading.

\section{CHANGE, NO CHANGE}

There was agreement among respondents that we are now both more aware and more outraged. Many respondents drew the parallel with child abuse, saying that while health professionals have always seen the problem, now it seems to be "managed, reported and supported" as never before. There is a sense of "a real will to change".

The bad news is that with the awareness and outrage comes a raft of difficulties. Respondents reported that the issue feels "scary", "there are no simple answers" and "it's a mess".

We admit to a lack of both knowledge and experience. On the most basic level, we are not always sure what to look for: "FGM may not be recognised, or lichen sclerosus may be misdiagnosed as FGM". On a more complex level, even when we do recognise it, "no one knows what to do". Nor is much mentoring available: "My superiors could not help when I asked. [That was] 18 months ago ... they have still not got back to me!!”. Add this to this a lack of common language and culture, and we are at a loss more often than we would like.

As a result, there is a further lack, this time of emotional confidence. Respondents spoke of a profession-wide sense of frustration that given our solely medical remit, we cannot support those we see to be in need. "We can feel very fearful about this area", "providers can find [the horrific stories] disturbing", "[these are] issues one cannot actually help with unless [the woman] is experiencing physical problems".

I further explored three specific issues with my respondents, starting from some headline phrases from the 2013 report Tackling FGM in the UK: Intercollegiate Recommendations for Identifying, Recording and Reporting (see Box 1).

\section{CULTURAL RITUAL OR CHILD ABUSE?}

The first of these issues is in the report's first recommendation, namely "Treat it as child abuse", with the extended explanation "FGM is not simply an exotic or cultural ritual that girls need to undergo".

Respondent reactions covered a wide spectrum. At one end there was clarity that "it is always abuse" and "it is a crime and the violation of a woman's rights". Clarity too that labelling the act as abuse is useful: "it has been the only way national and international action has been galvanised to address the harm", and that 
Box 1 Resources and additional reading

Department of Health. Commissioning Services to Support Women and Girls with Female Genital Mutilation. 2015. https:/l www.gov.uk/government/uploads/system/uploads/attachment_data/file/418549/2903842_DH_FGM_Commissioning_ Accessible.pdf [accessed 6 May 2015].

Department of Health. Female Genital Mutilation Risk and Safeguarding: Guidance for Professionals. 2015. https://www. gov.uk/government/uploads/system/uploads/attachment_data/file/418564/2903800_DH_FGM_Accessible_v0.1.pdf [accessed 6 May 2015].

Health Education England. FGM: e-Learning to Improve Awareness and Understanding of FGM. 2014. http://www.e-Ifh.org. uk/programmes/female-genital-mutilation [accessed 6 May 2015].

Home Office, the Right Honourable Norman Baker. Female Genital Mutilation: Resource Pack. 2014. https://www.gov.uk/ government/publications/female-genital-mutilation-resource-pack [accessed 6 May 2015].

RCM, RCN, RCOG, Equality Now, UNITE. Tackling FGM in the UK: Intercollegiate Recommendations for Identifying, Recording and Reporting. London, UK: Royal College of Midwives, 2013. [This document contains more detailed explanation of the summary phrases mentioned in this article.]

Royal College of Nursing (RCN). Female Genital Mutilation: A RCN Resource for Nursing and Midwifery Practice (2nd edn). 2015. http://www.rcn.org.uk/_data/assets/pdf_file/0010/608914/RCNguidance_FGM_WEB2.pdf [accessed 6 May 2015].

World Health Organization (WHO). Female Genital Mutilation. Integrating the Prevention and the Management of the Health Complications into the Curricula of Nursing and Midwifery. A Student's Manual. 2001. http://www.who.int/gender/ other_health/Studentsmanual.pdf [accessed 6 May 2015].

World Health Organization (WHO). Female Genital Mutilation. Integrating the Prevention and the Management of the Health Complications into the Curricula of Nursing and Midwifery. A Teacher's Guide. 2001. http://www.who.int/gender/ other_health/teachersguide.pdf [accessed 6 May 2015].

World Health Organization (WHO). Global Strategy to Stop Health-Care Providers from Performing Female Genital Mutilation. 2010. http://whqlibdoc.who.int/hq/2010/WHO_RHR_10.9_eng.pdf [accessed 6 May 2015].

Foundation for Women's Health Research and Development (FORWARD). African diaspora women's campaign and support organisation. http://www.forwarduk.org.uk

National Society for the Prevention of Cruelty to Children (NSPCC) UK helpline for women or those in danger. Tel: 0808 800 5000. E-mail: help@nspcc.org.uk. http://www.nspcc.org.uk

health professionals (even those from cultures where the practice is widespread) "are helped by this ... labelling ... as child abuse ... they can now point to the documentation and say that in the United Kingdom, things are different”.

At the other end of the spectrum, there is deep understanding that the issue is more complicated than the 'abuse' label would suggest. Respondents know that what we term mutilation is seen in its practising cultures as "the preservation of family reputation, culture and continuity". It is done for many reasons, including to support "the 'marriageability' of girls within societies where there are no prospects for progression ... other than as a wife and mother" and to help women "belong in the community [particularly when living as refugees in a strange land]". The point was made strongly by a number of respondents that "[it] is often done out of love and concern for the child".

There is also concern that labelling the practice as abuse may frustrate efforts to bring the practice to an end. "[It] will become even more hidden", "may undermine general health care for affected communities ... women who have been cut [may] stop attending for checkups and smears for fear of being discovered...”.

\section{REPORT - AND IF SO, TO WHOM?}

The second headline phrase on which I sought respondents' opinions was that "All [cases of FGM] should be referred to the police and support services".

This triggers almost universal wariness. In particular, respondents drew a distinction between women who have already undergone the procedure and girls in potential danger. Attitudes to the former are to some extent 'leave well alone', "the majority of cases are of women who have had this done many years before ... it is unclear to me what the police and support services are able to do" and "if [a woman] is not willing to be referred, she may feel that [doing so] is another assault".

Conversely, reporting to the support services "is appropriate where the FGM has just occurred or is about to occur". Though there are still concerns. "[When you] review whether their children are at risk ... I feel we lose the trust of the women.” Reporting 
to the police is seen as particularly unhelpful. Criminalisation "will alienate the very people we are trying to engage with to stop the practice - including [those] who had it done before it was declared a criminal offence". More than one respondent also suggested that reporting to police would be unrealistic due to lack of resources: "perhaps the police would like to send a representative to every potential service ... to facilitate these referrals?".

\section{SHOULD WE BE HELD ACCOUNTABLE?}

The final headline I highlighted was that "Frontline professionals [should be] held accountable". Again many respondents queried what this really implied. "Who decides what a 'frontline professional' is? What does accountable mean? How will this be enforced?" There was a huge willingness to step up to the task; "it should be our responsibility", but equally huge wariness that health professionals would be treated in the same way as were, so often in the past, "beleaguered social workers - blamed and hounded when things go wrong".

Perhaps the biggest cry, however, is that health professionals lack resources. "We need ... good knowledge ... education ... mentoring ... support ... practical systems ... monitoring", "there is a need for an understanding of the language used around FGM, both medical and colloquial - we need to know how to talk about this", "[we need] a point of contact - a trained member of staff, available at the place of work or a clear line of referral", "each College should swiftly develop key examples of good practice and make it a priority for inclusion in annual appraisal and CPD”.

Many of my respondents suggested that resources should also be channelled into empowering women suffering as result of, or at risk of, being cut. It was clear from comments just how helpful it is to work with affected communities both in this way and by building co-operation in the health setting. "With the [Somali] link worker ... it was amazing ... people very much wanted to attend", "Once we got talking with the community ... it was clear lots of people needed help". Health professionals' success is clearly very much tied into their ability to gain common ground with affected women. Remove that, and all the accountability measures in the world will fail.

\section{HOPE OF CHANGE}

In some ways, this exploration of attitudes can be seen as pessimistic. The health professionals I canvassed seemed to largely talk about what they felt was absent or required, to report their own or colleagues' frustration at the continued existence of female genital cutting and the blocks hindering its eradication.

But I don't see this as negative. For when I compare the high level of knowledge, commitment and pure passion about the issue to the uninformed passivity of my experience of 30 years ago, something has obviously changed. Though we must be wary of the child abuse label, there is a parallel here. We have faced and are continuing to challenge that issue. We can do so with this one.

My respondents are saying: "There has been amazing progress, leading to people who have experienced it speaking up and saying it must stop", "Health professionals are key to this. We can make a real difference" and "There is a huge social movement swelling both in the UK and internationally".

Competing interests None declared.

Provenance and peer review Commissioned; internally peer reviewed. 